\title{
RBEP
}

\section{Relações entre as representações sociais sobre o estudo e o desempenho na Prova Brasil}

\author{
Viviane Terezinha Koga ${ }^{\mathrm{I}}$ \\ Ademir José Rosso ${ }^{\text {II, III }}$
}

http://dx.doi.org/10.1590/S2176-6681/330913300

\section{Resumo}

Investiga as representações sociais (RS) dos alunos do $9^{\circ}$ ano sobre o estudo com base em sua abordagem estrutural e nos subsídios fornecidos pela Psicologia e Epistemologia Genética. A coleta de informações foi realizada mediante a aplicação de questionário $(\mathrm{N}=213)$, solicitando que os alunos evocassem palavras ou expressões relacionadas ao termo indutor "estudar é" e justificassem a expressão listada como a mais importante. As evocações foram analisadas com o auxílio dos softwares Evoc, e as justificativas, pela análise de conteúdo. Os resultados revelaram que os alunos possuem uma representação ambivalente sobre o estudo, o qual é visto ora de forma positiva, como algo importante para o futuro; ora de forma negativa, caracterizado como chato e cansativo. Elevadas ou baixas, as médias de desempenho na Prova Brasil estão associadas ao tempo dedicado ao estudo, ao hábito de estudar e ao controle escolar e familiar do estudo. Nas duas situações foram identificadas atitudes heterônomas e representações hegemônicas sobre o estudo, de modo que os desempenhos na Prova Brasil não se traduzem em uma maior autonomia no estudo nem em uma compreensão mais positiva deste.

Palavras-chave: representações sociais; autonomia no estudo; hábitos de estudo; Prova Brasil.

\footnotetext{
Doutoranda em Educação da Universidade Estadual de Ponta Grossa (UEPG), Ponta Grossa, Paraná, Brasil. E-mail: vivikoga28@hotmail. com

II Programa de Pós Graduação em Educação da Universidade Estadual de Ponta Grossa (UEPG), Ponta Grossa, Paraná, Brasil.E-mail: aj.rosso@ pq.cnpq.br

III Doutor em Educação pela Universidade Federal de Santa Catarina (UFSC), Florianópolis, Santa Catarina, Brasil.
} 


\section{Abstract \\ Relations between social representations of studying and performance in the Prova Brasil}

This article investigates the social representations (SR) of ninthgraders about studying, based on the theoretical background of SR in its structural approach and on the contributions offered by Psychology and Genetic Epistemology. Data collection was carried out with the use of questionnaire $(N=213)$, in which students were asked to react to the prompting term "studying is" and justify the listed expression as the most important. The evocations were analyzed with the aid of the software Evoc, and the justifications, through content analysis. Results revealed that students present an ambivalent representation of studying, which is sometimes seen positively, as something important for the future; but at other times it is seen negatively, characterized as boring and tiring. The Prova Brasil performance results, either good or bad, are associated with time dedicated to studying, studying habits and school and family control over studying. In both situations, heteronomous attitudes and hegemonic representations about studying were identified, so that Prova Brasil performance does not translate into higher autonomy in the studies nor a more positive comprehension of it.

Keywords: social representations; studying autonomy; studying habits; Prova Brasil.

\section{Introdução}

Há mais de uma década o Brasil está entre os países com níveis mais baixos de desempenho no Programa Internacional de Avaliação de Estudantes (Programme for International Student Assessment - Pisa) ${ }^{1}$ (OCDE, 2000, 2005, 2010; Brasil. Inep, 2008), ao mesmo tempo que se repetem os relatos do desinteresse dos alunos em aprender e participar das atividades escolares (Prediger; Berwanger; Mörs, 2009), fatos que vêm deixando os professores atônitos (Aquino, 1997). As reclamações recorrentes apontam para os "alunos-problema" (Aquino, 1997), "maus alunos" (Barreto, 1981) que "apresentam dificuldades de aprendizagem, que são indisciplinados e desinteressados" (Oliveira et al., 2004), apáticos e descomprometidos (Trevisol, 2007).

Ao levantarem as representações sociais (RS) sobre o sofrimento e desgaste no trabalho docente, Rosso e Camargo (2011) localizam o desinteresse dos alunos entre os elementos centrais das RS sobre o desgaste na docência. As possíveis causas para o desinteresse dos alunos seriam provenientes: a) de problemas familiares (Veríssimo; Andrade, 2001); b) das condições de vida fora da escola (Alves-Mazzotti, 2006); c) da progressão continuada que não reprova entre as séries (Neves; Boruchovitch, 
2004); d) dos conteúdos escolares ensinados de forma fragmentada e descontextualizada (Oliveira, M., 2009); e) da dificuldade de motivação para aprenderem determinados conteúdos; f) dos métodos de ensino que não condizem com as expectativas dos alunos (Trevisol, 2007); e g) dos conflitos existentes entre alunos e professores, em situações e momentos nos quais os alunos veem o estudo como obrigação e não como uma contribuição ao seu desenvolvimento pessoal (Oliveira, M., 2009).

Transitando entre as causas levantadas, e detendo-se principalmente na última delas, o presente artigo propõe relacionar as RS sobre o estudo e os hábitos de estudo. Investigam-se os alunos do $9^{\circ}$ ano do ensino fundamental por nesse ano ser aplicada a Prova Brasil ${ }^{2}$ - que contribui para o Índice de Desenvolvimento da Educação Básica $(\mathrm{Ideb})^{3}$ - e por haver proximidade entre a idade média desses alunos e a dos alunos que participam do Pisa.

Segundo resultados do Pisa, 20\% dos alunos brasileiros nunca leem; $50 \%$ leem entre 30 e 60 minutos; $20 \%$ leem em um intervalo de tempo que fica entre mais de 60 minutos a duas horas; e apenas 10\% leem mais que duas horas diariamente (OCDE, 2000, p. 116). O relatório também pontua que os alunos que leem pouco têm um desempenho inferior se comparado ao dos alunos que leem de 30 minutos a duas horas diárias (OCDE, 2000, p. 115). A leitura é indispensável ao aprendizado, aos hábitos de estudo e ao rendimento escolar dos alunos, e muitos que poderiam obter sucesso na escola não obtêm devido à ausência de hábitos de estudo e de leitura. Essa falta pode se agravar com a idade, à medida que os alunos passam de uma série para outra.

Os níveis de desempenho nas avaliações externas nacionais (Prova Brasil) ou internacionais (Pisa) ligam-se, entre outros fatores, aos hábitos de estudo. Disso advém que as intervenções no sistema do ensino passam, necessariamente, pela mudança da cultura escolar e de suas RS (Jodelet, 2007), ou seja, das formas como os alunos vivenciam, reconhecem, explicam e elaboram o ato de estudar. As diferenças existentes entre as escolas nas médias de desempenho dos alunos na Prova Brasil poderiam indicar diferentes práticas escolares e RS do estudo. Por isso a pesquisa buscou compreender as RS dos alunos sobre o estudo em função da média de desempenho desses alunos na Prova Brasil e dos resultados obtidos por suas escolas no Ideb, nos anos 2005, 2007, 2009 e 2011.

As RS dos pais, professores e alunos sobre a instituição escolar e o processo de escolarização formal são apresentadas no artigo "Pedagogia, futuro e liberdade: a instituição escolar representada por professores, pais e alunos", de Oliveira et al. (2004). Para os alunos, a escola significa mobilidade social, entretanto, a escolarização "ora é vista como positiva e estimulante, e ora é vista como ruim, desinteressante e cansativa" (p. 35). Da mesma forma, os alunos creem que, pela escola, concretizarão as aspirações futuras; atribuem, pois, grande importância ao estudo, integrando-o em suas representações como ascensão social, embora o vejam também como fonte de experiências desagradáveis (Salles, 1995).

Assim, o objetivo central deste trabalho consiste em desvelar quais são as RS que os alunos do $9^{\circ}$ ano do ensino fundamental possuem sobre

\footnotetext{
A Prova Brasil, criada em 2005, caracteriza-se como uma avaliação diagnóstica realizada por amostragem a cada dois anos com os alunos do $5^{\circ}$ e $9^{\circ}$ ano do ensino fundamental das escolas públicas das redes municipais, estaduais e federal, com o objetivo de avaliar a qualidade do ensino ministrado nas escolas públicas. Essa avaliação contempla conhecimentos de língua portuguesa e matemática.

3 O Ideb, criado em 2007 , monitora a educação e estabelece metas, apresentando o resultado de cada escola. Ele é composto pela média de aprovação, obtida por meio do censo escolar, e a média de pontuação obtida pelos alunos na Prova Brasil.
} 
estudo, bem como apontar se essas representações estão associadas aos diferentes desempenhos na Prova Brasil, e se estão, ou não, associadas à autonomia intelectual dos alunos. Ao captar a estrutura interna das RS, objetiva-se compreender a perspectiva dos alunos em relação ao estudo. A teoria das representações sociais, em especial a abordagem estrutural (Abric, 2003), fundamentou a discussão sobre o contexto das vivências concernentes ao estudo. Para a prática educativa, com o intuito de analisar a autonomia intelectual, buscou-se apoio na psicologia genética (Piaget, 1994).

\section{Hábito e representação social do estudo}

Nas conversas dos professores não é raro o aparecimento de queixas de que os alunos não estudam, ou que o fazem somente no período das provas, movidos pela necessidade de aprovação no sistema escolar ou pela cobrança dos pais e professores. Esse é um indicativo de falhas no desenvolvimento da autonomia no estudo e no trabalho educativo, que deveria ser cultivada sistematicamente para manter os alunos estudando, independentemente dos fatores externos às suas vontades (Nunes, 2006).

Autonomia intelectual "significa ser governado por si mesmo, a partir da capacidade de levar em conta fatores relevantes". (Kamii, 1993, p. 75). As bases para o desenvolvimento dessa autonomia estão nas relações de cooperação que se estabelecem, favorecendo "a consciência [que] considera como necessário um ideal, independentemente de qualquer pressão exterior". (Freitas, 2003, p. 92). Assim, seu desenvolvimento necessita de um ambiente de trocas de pontos de vista, tomada de decisões, "enquanto amadurecimento do ser para si" e do seu "vir a ser". (Freire, 1996, p. 107). Desse modo, quando o aluno participa da construção das regras sobre o estudo, sente-se parte integrante de um grupo e de valores circulantes, ao mesmo tempo que adquire autonomia e se desenvolve intelectualmente (Ferreira, 2001).

Ao contrário, silenciar no campo social e moral impede a liberdade de expressão das ideias também no campo intelectual (Kamii, 1993). A heteronomia representa a primeira forma encontrada pela criança para regular a ação oriunda das relações instituídas com os adultos e apoia-se na dificuldade de compreensão das normas, que pode ser superada no "vir a ser" do processo educativo. Se na heteronomia, como o próprio nome indica, a norma provém do outro por incompreensão ou moral da coação, o hábito de estudo nessas condições não se mantém, "pois depende de fatores externos: em alguns contextos a pessoa segue determinados valores, e em outros não mais os segue". (Vinha; Tognetta, 2009, p. 529). Se for cobrada e coagida, estuda; desaparecendo a pressão, não estuda.

Devido à assimetria existente na relação com os mais velhos, a heteronomia das crianças passa a ser rejeitada no período da adolescência, quando o adolescente tende a revisar seus próprios princípios, a fim de construir, para si, uma representação do mundo, um projeto de vida (Freitas, 2003). No entanto, se as escolas tendem a negar a participação dos alunos 
na elaboração das regras e priorizam mecanismos de controle nas relações e práticas sociais vigentes, tendem a manter, pela coação, os alunos em estados heterônomos (Piaget, 1994).

$\mathrm{O}$ ato de estudar dos alunos do $9^{\circ}$ ano merece atenção especial devido, sobretudo, à convergência das faixas etárias correspondentes ao Pisa e à Prova Brasil; às informações do Pisa sobre o tempo dedicado à leitura e, por extensão, ao estudo; às reclamações dos professores acerca do desinteresse dos alunos pelo estudo (segundo os docentes, apenas uma minoria dos alunos estuda de forma autônoma). Apesar de ser relevante, ainda é pequena a exigência da escola em relação ao estudo (Magro, 1979) e às iniciativas adotadas para desenvolvê-lo (Souza, 1985), fato que favorece a crença de que o aluno não precisa estudar (Magro, 1979; Alves-Mazzotti, 2006).

Desde seu ingresso na vida escolar, por volta dos sete anos, o aluno já mantém "uma atitude específica perante a escola e o aprendizado, mas também uma espécie de predisposição ou intenção na hora de aprender". (Bueno-Álvarez, 2005, p. 52). Por outro lado, no decorrer da vivência escolar, esse aluno vai se deparando com situações que envolvem o ato de estudar. É assim que ele constrói e partilha, socialmente, percepções, atitudes e imagens que circulam e fazem parte da rotina escolar (Jovchelovitch, 1999; Jodelet, 2007).

As RS caracterizam-se por expressarem a relação existente entre o sujeito e o objeto - sujeito que é essencialmente ativo ao reapresentar um determinado objeto, reconstruindo-o, atribuindo-lhe um sentido próprio, revelando sua função simbólica. Ao deparar-se com um objeto novo, o sujeito aproxima-o dos conhecimentos de que dispõe, instituindo-se, assim, uma linguagem particular assentada em valores e em conceitos (Moscovici, 1978; Alves-Mazzotti, 2006). Logo, as RS não são apenas "opiniões sobre" ou "imagens de" um determinado objeto, mas configuram-se como "teorias coletivas destinadas à interpretação e elaboração do real". Portanto, possuem uma lógica e uma linguagem particular baseadas em valores e conceitos que "determinam o campo das comunicações possíveis dos valores ou das idéias presentes nas visões compartilhadas pelos grupos e regem, subsequentemente, as condutas desejáveis ou admitidas". (Moscovici, 1978, p. 51).

O estudo das RS pode ser feito de acordo com três abordagens teóricas: sociogenética, sociodinâmica e estrutural. A primeira diz respeito aos "processos de construção das RS"; a segunda "descreve a sua estruturação interna"; e a terceira concentra-se "em suas relações com as inserções sociais dos indivíduos" (Dechamps; Moliner, 2009, p. 125). Neste trabalho, as representações do estudo serão discutidas com base na abordagem estrutural, na qual toda RS é organizada em torno de um núcleo central que se caracteriza como um ponto de difícil alteração, que concentra um valor comum atribuído pelos sujeitos a determinado objeto. Por meio desse núcleo são criados e transformados os significados de uma representação (função geradora); ele determina a natureza das ligações entre os elementos, unindo os elementos de uma representação (função organizadora); seus elementos são mais estáveis e, portanto, resistentes à mudança (função 
estabilizadora) (Deschamps; Moliner, 2009; Alves-Mazzotti, 2006; Abric, 2003; Sá, 1996).

Ao núcleo central, são atribuídas duas dimensões distintas: a dimensão funcional, ligada à natureza do objeto representado, e a dimensão normativa, que diz respeito aos valores e normas que pertencem ao meio social do grupo (Sá, 1996). Todavia, o núcleo central não dá conta de esgotar todo o conteúdo e as formas de funcionamento da representação no cotidiano. Para tanto existe o sistema periférico, composto por outros elementos que entram na composição da representação. Ele constitui a parte mais acessível e operante desta e tem sua importância relacionada ao funcionamento e à dinâmica das representações. Segundo Sá (1996), o sistema periférico provê a "interface entre a realidade concreta e o sistema central", e "é graças a ele que a representação pode se ancorar à realidade do momento". Por meio dele, as representações aparecem no cotidiano e os elementos centrais dessas representações não podem ser compreendidos senão em uma dialética contínua com os elementos periféricos (Alves-Mazzotti, 2007).

\section{Metodologia e sujeitos da pesquisa}

Foi apresentado aos alunos do $9^{\circ}$ ano, de três escolas estaduais da cidade de Ponta Grossa (PR), um instrumento, composto de duas partes, para identificar a estrutura da RS do estudo. Na primeira parte, objetivava-se recolher algumas informações gerais (idade, sexo, recuperação, reprovação, horas de estudo) a fim de descrever os alunos e seus hábitos de estudo. Na segunda, propunha-se uma questão de associação livre de palavras (Sá, 1996), na qual os alunos deveriam expressar espontaneamente seis palavras ou expressões diante do termo indutor: "estudar é". Após listar e enumerar as palavras segundo a ordem de importância atribuída a elas, os alunos eram solicitados a justificar, em um pequeno texto, a escolha da palavra indicada em primeiro lugar.

O instrumento foi aplicado no mês de novembro de 2010, com o consentimento das escolas, durante aulas cedidas pelos professores, seguindo os cuidados éticos definidos por Spink (2000): o consentimento informado; o resguardo das relações de poder abusivas; e, ainda, o anonimato.

Optou-se por investigar três escolas (A, B e C) em virtude da média de desempenho dos alunos dessas escolas na Prova Brasil e, ainda, em virtude dos resultados alcançados por elas no Ideb, nos anos 2005, 2007, 2009 e 2011. Preferiu-se agrupar as escolas A e B, separando a escola C, durante a análise dos dados, pois as escolas A e B obtiveram resultados no Ideb acima da média projetada para esse período, enquanto a escola $\mathrm{C}$ ficou abaixo dos resultados esperados. Além disso, com exceção do ano de 2005, a média de desempenho dos alunos na Prova Brasil, nas escolas A e $\mathrm{B}$, foi superior à média dos alunos da escola $\mathrm{C}$, como se pode verificar na tabela 1, apresentada a seguir. 
Tabela 1 - Média de Desempenho das Escolas na Prova Brasil e Resultados do Ideb

\begin{tabular}{|c|c|c|c|c|c|c|c|c|c|c|c|}
\multicolumn{70}{|c|}{ Anos } \\
\hline
\end{tabular}

Fonte: Brasil. Inep, [s. d.].

Esses três estabelecimentos de ensino compõem o universo de 43 escolas da rede estadual de Ponta Grossa (PR) que possuem o $9^{\circ}$ ano, no qual houve 4.656 matrículas em 2010 (Paraná, 2012). Na classificação das escolas paranaenses, segundo seus resultados no Ideb, a escola A aparece entre as 15 melhores do estado e como a segunda melhor da cidade; a escola B está entre as 70 melhores do estado e é considerada a terceira melhor da cidade; e a escola $\mathrm{C}$ aparece em posição inferior à de 1.200 escolas do estado, estando entre as cinco escolas da cidade com as menores médias no Ideb (Brasil. Inep, 2011).

A amostragem foi de 213 alunos, considerando a autorização expressa de divulgação das informações. Destes, $57,7 \%$ são das escolas A e B e $42,3 \%$, da escola C. Nas escolas A e B, 65\% dos alunos disseram já ter ficado em recuperação, afirmação de $50 \%$ dos alunos da escola C. No que se refere à reprovação, observou-se que, apesar de a escola C ter obtido uma porcentagem menor de alunos em recuperação, 33\% destes assinalaram já terem sido reprovados, diante da afirmativa de reprovação de $27 \%$ dos alunos das escolas A e B.

Sobre o estudo, apurou-se que nas escolas A e B apenas 3\% dos alunos afirmaram que não estudam regularmente fora da escola, enquanto, na escola C, 23\% dos alunos fizeram tal afirmação. Por fim, ao serem questionados a respeito do tempo médio que dedicam ao estudo semanalmente, observou-se que os alunos das escolas A e B indicaram que estudam em média 3,13 horas, ao passo que os alunos da escola $\mathrm{C}$ declararam estudar em média 2,17 horas.

Após a aplicação do instrumento, foram agrupadas as palavras e/ou expressões evocadas pelo termo indutor "estudar é", levando-se em conta os sinônimos e as palavras com o mesmo significado semântico. Depois desse tratamento, procedeu-se à análise em questão, com o apoio do software Ensemble de Programmes Permettant l'Analyse des Evocations (Evoc) -, de Vergés (2005), que auxilia na identificação dos prováveis elementos que compõem o núcleo central e o sistema periférico. Posteriormente, com a utilização da análise de conteúdo proposta por Bardin (1977), foram analisadas as justificativas de escolha da palavra listada em primeiro lugar. 
Por fim, buscou-se identificar as ligações da RS do estudo com a análise de similitude, que visa verificar as semelhanças ou afinidades existentes entre as palavras que foram evocadas pelos alunos, ou seja, o poder associativo dos elementos que compõem o núcleo central e o sistema periférico, por meio do exame da árvore máxima de similitude. É importante destacar que a soma das arestas dessa árvore caracteriza-se como a maior entre as encontradas em todas as árvores possíveis (Tura, 1998).

\section{Análise das informações coletadas}

Do total de 213 alunos informantes, obteve-se uma lista com 1.240 palavras, das quais 234 eram diferentes. Para a composição dos quatro quadrantes, foram descartadas, durante o tratamento no Evoc, as palavras cuja frequência mínima era menor que $11 \%$ ou 5\%. Do total de 234 palavras, 33 estão distribuídas na Tabela 2, compondo os quatro quadrantes, nos quais pode ser observada a ordem média de evocação (OME) - que foi de 3,4 - e a frequência média de evocação (Freq.) - que foi 27. Esses valores foram extraídos do relatório fornecido pelo Evoc.

A Tabela 2 é composta por quatro quadrantes: os superiores, acima da borda pontilhada, são compostos por palavras com frequências $\geq 27$; e os inferiores, por palavras com frequências $<27$. Da mesma forma, os quadrantes da esquerda têm $\mathrm{OME}<3,4$; e os da direita, $\geq 3,4$. Assim, os possíveis elementos que compõem o núcleo central estão localizados no quadrante superior esquerdo, no qual podem ser observadas as palavras que concomitantemente foram evocadas com maior frequência e aparecem nas primeiras posições. O quadrante superior direito e o inferior esquerdo apresentam somente uma dessas condições e, por esse motivo, possuem elementos menos relevantes na estrutura da RS, mas que são significativos em sua organização. Já o quadrante inferior direito, por possuir baixa frequência e elevada OME, compõe a periferia da RS.

Ao analisar a constituição dos quadrantes, observa-se a presença constante de uma ambivalência em face do estudo: ora é visto de forma positiva como importante para o futuro, ora é visto de forma negativa como chato e cansativo.

No primeiro quadrante, entre os possíveis elementos que constituem o núcleo central, aparecem as palavras esforço, futuro e importante, que se referem ao estudo enquanto aquisição do conhecimento e via de ascensão social. Esses elementos tiveram maior contribuição dos alunos da escola C, aqueles que têm desempenhos mais baixos na Prova Brasil, e indicam forte ligação com os valores e normas sociais associadas ao estudo: estudar é importante para conseguir um futuro melhor. O estudo, para os alunos da escola C, é visto como uma via que facilita a mobilidade social. A palavra futuro coloca-se como um ideal a ser alcançado por meio do estudo; a partir do esforço e da responsabilidade, edifica-se um caminho para um futuro diferente daquele esperado em função da classe social desses alunos. 


\section{Tabela 2 - Possíveis Elementos que Compõem a Estrutura da Representação Social do Estudo}

\begin{tabular}{|c|c|c|c|c|c|}
\hline \multirow{2}{*}{ Palavras } & Freq. & OME & \multirow[b]{2}{*}{ Palavras } & Freq. & OME \\
\hline & $\geq 27$ & $<3,4$ & & $\geq 27$ & $\geq 3,4$ \\
\hline Esforço & 37 & 2,89 & Aprendizagem & 44 & 3,40 \\
\hline Futuro & 81 & 2,59 & Cansativo & 49 & 3,85 \\
\hline Importante & 49 & 1,65 & Chatice & 85 & 3,61 \\
\hline Preguiça & 57 & 3,31 & Livros & 30 & 4,00 \\
\hline Provas & 39 & 2,89 & Ruim & 31 & 3,80 \\
\hline Sono & 33 & 3,39 & & & \\
\hline Palavras & $<27$ & $<3,4$ & Palavras & $<27$ & $\geq 3,4$ \\
\hline Aprovação & 26 & 3,26 & Bom & 22 & 4,36 \\
\hline Conhecimento & 26 & 2,76 & Cadernos & 20 & 3,70 \\
\hline Disciplinas & 11 & 3,09 & Concentração & 11 & 3,81 \\
\hline Emprego & 19 & 3,36 & Dedicação & 16 & 3,56 \\
\hline Inteligência & 14 & 2,85 & Difícil & 12 & 4,08 \\
\hline Inútil & 11 & 3,27 & Escola & 19 & 3,52 \\
\hline Notas & 11 & 3,00 & Leitura & 12 & 3,41 \\
\hline Obrigação & 26 & 3,03 & Raiva & 17 & 3,41 \\
\hline Responsabilidade & 18 & 2,83 & Respeito & 12 & 4,33 \\
\hline Tempo & 13 & 3,38 & Tarefas & 14 & 3,57 \\
\hline Trabalho & 21 & 3,28 & & & \\
\hline Vontade & 15 & 3,20 & & & \\
\hline
\end{tabular}

Fonte: elaboração própria.

Entretanto, junto a esses elementos aparecem as palavras provas, preguiça e sono, as quais podem ser indícios de heteronomia no estudo. Isso pode ser verificado também no segundo quadrante, no qual, em meio às palavras com forte tendência à centralidade, aparecem os termos chatice e cansativo. Ligados à natureza do estudo para os alunos das escolas $\mathrm{A} \mathrm{e}$ $\mathrm{B}$, esses dois termos evidenciam maior rejeição ao estudo, o que pode ser indicativo de maior heteronomia, bem como de reação aos mecanismos do controle escolar. Essas informações - que estariam associadas à adolescência e que, por conseguinte, definem a homogeneidade do grupo de alunos sugerem que os alunos estão remodelando e/ou reconstituindo o valor dado ao estudo.

Por fim, ao observar os termos que se apresentam na periferia propriamente dita (caderno, escola, leitura, tarefas, concentração, dedicação, difícil, entre outros), verifica-se que remetem os alunos ao cotidiano do estudo, o qual demanda dedicação e, por vezes, constitui uma tarefa difícil que exige concentração.

Ao analisar o conteúdo das justificativas dos alunos para as palavras e/ou expressões listadas em primeiro lugar (Bardin, 1977), foi possível 
entender melhor o sentido que lhes foi atribuído, além de visualizar o contexto em que foram citadas.

A palavra futuro, que recebeu maior contribuição dos alunos da escola C, está ligada a situações do estudo sobre as quais a ideologia da sociedade ou as situações sociais intervêm, fazendo com que os alunos entendam que para ter um futuro bom é necessário estudar. Há nisso uma representação do estudo como forma de conseguir um bom emprego, ter uma vida melhor e, assim, poder ajudar as pessoas, em especial os familiares. Também há que se considerar que os alunos da escola $C$ vivem em uma região em que as condições socioeconômicas são mais precárias em comparação com as condições das outras duas escolas. Assim, o estudo para esses alunos é uma alternativa, senão o único meio de ser alguém no futuro, ou seja, de conseguir sair da situação econômica e social em que se encontram.

Quero me formar para eu ser alguém na vida e conseguir dar um futuro melhor para minha família.

É importante estudar! Porque sem estudar a gente não é ninguém na vida. Eu penso que tenho que estudar porque não quero ser um catador de lixo, o estudo é tudo na vida das pessoas.

Eu quero um futuro melhor e estudando eu sei que eu vou trabalhar e ter uma vida boa e a escolha que eu fizer eu sei que serei muito feliz.

Sem estudar você não terá um futuro e uma carreira para escolher. Sem estudo você não é nada na vida.

Em um contexto análogo, a expressão importante surge como um aspecto normativo da representação do estudo, que expressa a relação existente entre os alunos da escola C e o estudo, fortemente marcada pela ideologia e pela normatização do meio social em que esses sujeitos se encontram inseridos desde o nascimento, antes mesmo de aprender a falar, em um contexto no qual são submetidos a um sistema de regras e assim vão tomando consciência das obrigações das pessoas no dia a dia (Piaget, 1994). Ao representar o estudo como importante, os alunos expressam uma representação social tradicional, fortemente enraizada na história e na cultura da sociedade.

Estudar é importante para o futuro, porque com os estudos eu posso ter um futuro muito bom, um trabalho que me dê uma condição financeira boa para que eu possa me manter sozinha, além do conhecimento que levarei por toda a vida.

O estudo nos ajuda a conseguir um bom futuro, obter sucesso no futuro com um bom trabalho, por isso ele é muito importante.

Sei que se eu não me dedicar aos estudos não vou ter um futuro bom. O maior problema com certeza é o mercado de trabalho, todos esperam por um bom emprego, a concorrência é grande, consegue quem estiver melhor preparado.

É importante para adquirirmos conhecimento, chances de conseguirmos um emprego melhor, melhorar a comunicação e termos um futuro melhor, porque hoje em dia sem estudo a gente não consegue nada. 
Por outro lado, o elemento preguiça se contrapõe às representações positivas do estudo observadas nas expressões analisadas até então. Esse elemento é profundamente marcado pela heteronomia, evidenciada pelas falas "a mãe manda estudar", "a professora manda estudar", "devo estudar". Nota-se nessas expressões que as regras morais relacionadas ao estudo vêm sendo transmitidas verbalmente pelos pais e professores, mas, como já discutido anteriormente, elas são construídas somente por meio de relações interpessoais, na escola, com os professores, ou em casa, com os pais. Entretanto, esses segmentos de texto constituem a base comum, que é coletiva e partilhada entre os alunos das escolas A e B. Assim, os alunos que têm os melhores desempenhos na Prova Brasil destacam nas suas justificativas "o sono", "a preguiça de lembrar toda a matéria" e de "frequentar as aulas", a falta de vontade de "aguentar" os professores e as aulas, ambos considerados chatos.

Quando me lembro de estudar, me dá um cansaço, uma preguiça, só de lembrar toda aquela matéria que tem que ler, aí me dá sono.

Sempre que a minha mãe manda estudar me dá muita preguiça, pois, na maioria das vezes, estamos no computador ou vendo televisão, não estamos pensando em estudar.

Toda vez que devo estudar para algo me dá aquela preguiça. Quando a professora fala para estudar eu penso: que preguiça! quero dormir e não estudar.

Estudar dá preguiça já na hora de levantar cedo, pensar em aguentar aulas e professores chatos, mas também tenho uma forcinha de vontade de ir para a escola para ver os amigos e porque vai ser bom para o meu futuro.

Da mesma forma, a expressão chatice é coletivamente partilhada entre os alunos. Esse termo aparece mais relacionado ao ambiente escolar, às situações que lembram o dia a dia na escola, como os conteúdos, as provas, os professores e as aulas.

Quando se fala em estudar, vem à mente as provas que vão avaliar meu rendimento na escola e comprovar se eu realmente aprendi os conteúdos apresentados em sala de aula.

Basta vir para a escola e ter aquela aula chata para desistir de novo e assim se vai, um dia com disposição, e outro nem tanto.

Tem que ir todos os dias para a escola, apesar de ser chato, é legal ao mesmo tempo.

É chato porque você perde um pouco de tempo.

Na última etapa, as palavras foram submetidas à análise de similitude, que possibilita analisar a conexidade e o poder associativo entre elas, de modo a organizar os elementos que compõem a RS, mostrando suas relações a partir do número mínimo de dez coocorrências, ou seja, mostrando a possibilidade de as palavras ocorrerem uma(s) em combinação com a(s) outra(s). Essa análise auxilia para uma melhor compreensão do sentido atribuído às palavras apresentadas. 
A análise de similitude utilizou o conjunto de dados proveniente da análise do Evoc, possibilitando, assim, a visualização de um gráfico denominado "árvore máxima" (Tura, 1998), apresentado na Figura 1. As palavras que compõem a árvore máxima de similitude podem formar figuras abertas (arestas soltas), ou podem conectar-se formando figuras fechadas (quadrados, triângulos, losangos etc.). A força de ligação entre esses elementos é indicada por meio da espessura das arestas (AlvesMazotti, 2007). Nos vértices (junções) da árvore podem ser visualizadas as palavras, e nas arestas (intersecções) que as ligam é possível observar a coocorrência das evocações. As palavras que foram evocadas mais vezes apresentam, entre parênteses, a frequência de evocação.

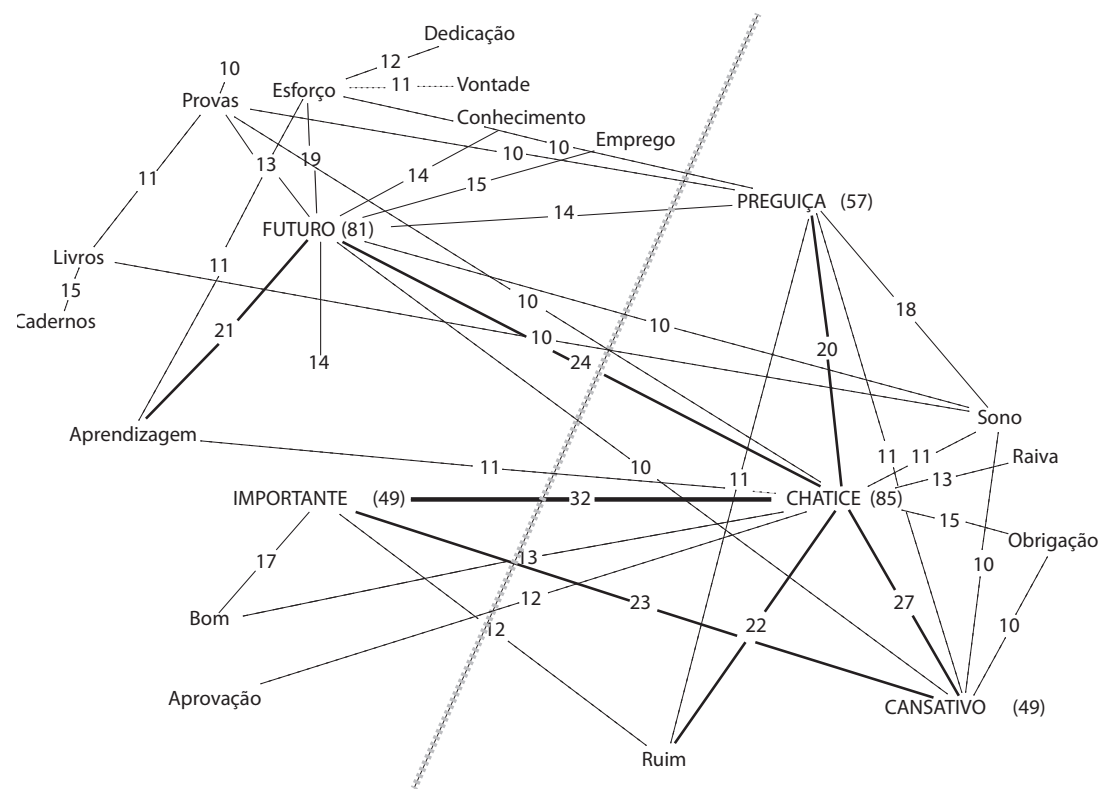

Figura 1 - Árvore Máxima de Similitude

Fonte: elaboração própria.

Na Figura 1, pode-se verificar a árvore máxima de similitude, na qual as palavras futuro-chatice constituem o eixo central, com maior frequência de evocações, porém não de coocorrências. São os prováveis termos centrais e organizadores da RS do estudo, uma vez que a palavra chatice possui doze arestas, tendo, assim, maior poder associativo que a palavra futuro, que possui dez arestas. Assim, de um lado, a palavra chatice, por sua OME, mostra-se próxima do núcleo central, com alto poder organizativo; e, de outro, por ser fruto de uma cultura posterior e própria da adolescência, secunda as convenções sociais e culturais sobre o estudo.

A associação futuro-chatice indica, em porcentagem, uma partilha menor entre os informantes do que chatice-importante ou chatice-cansativo. Ao contrário do esperado, a palavra importante está mais associada à chatice do que ao termo futuro, podendo indicar um caráter apenas formal 
para essa evocação. Entretanto, isso também é um indicativo de que os termos importante e chatice podem ser convergentes na RS do estudo. Dito de outra forma, um aluno pode, ao mesmo tempo, atribuir ao estudo ambas as apreciações, o que indica uma transição valorativa.

Como a palavra chatice possui maior número de elementos a ela ligados, organiza as ideias de que estudar é uma chatice, é cansativo, é ruim, dá preguiça, sono e raiva, mas serve para aprovação e ainda é importante para o futuro. Da mesma forma, a palavra aprovação não está conectada aos termos aprendizagem, esforço, ou mesmo a conhecimento e provas, livros e cadernos, que mediatizam o estudar. Com essas informações a ambiguidade na RS do estudo não está somente nos termos evocados, mas assenta-se em sua estrutura cindida.

Há uma cisão na RS do estudo, que pode ser observada em triângulos da figura que articulam, em seus vértices, elementos positivos e negativos, como aprendizagem, futuro e chatice; bom, importante e chatice; importante, cansativo e chatice; futuro, preguiça e chatice; e importante, cansativo e chatice.

Para Moscovici (2012, p. 68) essas apreciações favoráveis e desfavoráveis correspondem a atitudes. ${ }^{4}$ Segundo o autor, obtemos informações e representamos algo unicamente depois de termos tomado uma posição simbólica. Assim, de um lado, as atitudes apontam a orientação global, a tomada de posição dos alunos em relação ao estudo, que é discutido pela sociedade em geral e pelos alunos em particular; e, de outro, constituem uma fórmula valorizada pela sociedade na qual os alunos estão inseridos. As atitudes ainda expressam, no plano social, as convenções do que é permitido ou não comunicar sobre o estudo. Portanto, os conhecimentos circulantes sobre o estudo, ou sobre sua função social, associam-se à atitude dos alunos em relação a ele.

A análise da árvore de similitude aponta para duas atitudes em relação ao estudo. Do lado esquerdo, estão as palavras futuro, emprego, aprendizagem e conhecimento, que expressam percepções positivas sobre o estudo; e, do lado direito, as palavras chatice, preguiça, raiva e sono, que se referem à rejeição ao estudo. Na árvore, pode-se apreender que a atitude desfavorável possui uma tendência organizativa maior do que a favorável.

Isso confirma mais uma vez a oposição entre os termos que constituem a representação dos alunos sobre o estudo, sugerindo novamente duas tomadas de posições divergentes, o que pode ser explicado também devido à faixa etária em que os alunos se encontram, pois na adolescência acontecem intensas transformações tanto de ordem biológica como psicológica e social. É um período de conflitos. Além disso, nessa faixa etária há uma conscientização da necessidade de inserção no meio social e o adolescente toma para si o próprio destino pessoal e futuro profissional, bem como apresenta a necessidade de realização e de autonomia (Fernandes, 1990; Freitas, 2003).

\footnotetext{
4 O termo atitude é empregado em virtude de que, para visualizarmos de forma global o conteúdo e o sentido de uma RS, ela deve ser necessariamente constituída por três dimensões: conhecimentos, atitudes e imagens. A atitude caracteriza-se como a mais frequente das três dimensões e é a primeira a aparecer em uma RS. Ela corresponde à direção, que pode ser favorável ou desfavorável, sendo sempre expressa por meio de respostas avaliativas. Atribui-se a ela, ainda, "uma virtude preditiva, uma vez que, segundo o que o individuo diz, pode-se deduzir o que ele vai fazer". (Moscovici, 1978, p. 46).
} 


\section{Considerações finais}

As informações levantadas e analisadas permitem uma compreensão crítica dos resultados do Ideb, bem como do desempenho na Prova Brasil, dos alunos das três escolas investigadas, em relação à autonomia no estudo. Avaliou-se que o Ideb avança em diagnosticar as escolas que possuem alunos com baixo rendimento escolar e em orientar as ações políticas. Porém, é somente um diagnóstico que não revela o processo educativo rumo à formação de hábitos de estudos e autonomia intelectual. Desse modo, a elevação do Ideb não aumenta, necessariamente, a qualidade do ensino e do estudo (Setúbal, 2010). É necessário, sim, elevar o Ideb, mas, do ponto de vista educativo, há outros aspectos a se ater, como o desempenho nas avaliações externas e a autonomia dos alunos diante do estudo.

É possível afirmar, com base neste trabalho, que a diferença na média de desempenho dos alunos na Prova Brasil, nas três escolas investigadas, ocorre devido à relação existente entre essa média e os estratos socioeconômicos atendidos pelas escolas, assim como os hábitos de estudo. Os alunos das escolas A e B estudam semanalmente uma hora a mais, e essas escolas e suas famílias possuem mecanismos de controle mais efetivos sobre o estudo e o desempenho dos alunos. Esse dado é significativo se for considerado que o desempenho em avaliações externas, como a Prova Brasil e o Pisa, depende das horas dedicadas ao estudo. Assim, os alunos que estudam mais alcançarão uma pontuação melhor, como já foi demonstrado pelos relatórios do Pisa (OCDE, 2000).

Ainda, analisando-se os dados censitários referentes à variável reprovação, verifica-se que uma porcentagem maior de alunos da escola C (menor Ideb), se comparada às das escolas A e B, afirma já ter sido reprovada. Esse dado certamente possui relação direta com o resultado do Ideb, pois se trata de um índice calculado pela razão entre a pontuação dos alunos na Prova Brasil e a taxa média de aprovação desses alunos na correspondente etapa de ensino. Dessa forma, se a escola reprova mais, consequentemente terá uma menor nota no Ideb.

O presente trabalho partiu da suposição de que existiam diferenças nas representações dos alunos em escolas distintas, por isso foram escolhidas três escolas de acordo com a média dos desempenhos de seus alunos na Prova Brasil e com os resultados alcançados por elas no Ideb. A pesquisa pelas RS dos alunos do $9^{\circ}$ ano do ensino fundamental sobre estudo, a fim de verificar se elas estão associadas aos diferentes resultados na Prova Brasil e no Ideb, bem como à autonomia intelectual dos alunos, verificou que tanto as RS quanto os bons resultados relacionam-se mais a mecanismos de controle. Tais mecanismos são geralmente expressos por relações de coação que os alunos mantêm com seus pais ("minha mãe manda estudar") e professores ("a professora manda estudar"), nas quais a norma, o "dever estudar", provém de outras pessoas. Assim, mesmo que os alunos das escolas A e 
B estudem mais que os alunos da escola $C$, eles tendem a rejeitar mais o estudo, estando mais presentes em sua associação de palavras termos que expressam a rejeição ao estudo e apontam para uma atitude mais negativa em relação a ele. No entanto, vale a pena ressaltar que "ninguém é sujeito da autonomia de ninguém" (Freire, 1996, p. 107), e que a heteronomia não se sustenta por depender de fatores externos (Vinha; Tognetta, 2009). Quanto ao hábito de estudo, verificou-se que ainda é grande o número de alunos que afirma não estudar ou estudar somente nos períodos de provas. Esses resultados confirmaram o estudo realizado por Nunes (2006).

Evidenciou-se também que há ambivalência na RS dos alunos, uma vez que o sentido e os significados são conflitantes. Contudo, essa ambivalência aparece, em alguns casos, como convergente na RS do estudo. É possível, então, que os alunos estejam remodelando ou reconstituindo o modo como pensam o estudo, pois sua representação é expressa por dois polos que são constituídos por elementos que se referem a atitudes positivas e negativas, os quais se mostraram constantes em todas as etapas da análise realizada neste trabalho.

Os elementos futuro e importante são provenientes do sistema de valores dos alunos e são responsáveis pelas suas atitudes ante o estudo; e os elementos chatice e cansativo estão associados às características com que os alunos descrevem o estudo em suas práticas (Abric, 2003), em se considerando que o tipo de relação que eles estabelecem com o estudo autônoma ou heterônoma - pode ativar esses elementos de forma distinta. Segundo Campos (2003), alguns objetos que possuem carga ideológica (como é o caso do estudo) são característicos por ativar os elementos normativos. Logo, os alunos apresentam um discurso condizente com o que, antes mesmo do nascimento deles, está posto na sociedade: estudar é importante para o futuro e para que eles consigam sair da situação econômica em que se encontram.

Por fim, considera-se que as RS constituem-se num campo fértil, que pode ser ainda mais explorado em trabalhos relacionados aos hábitos de estudo, pois poucas são as investigações voltadas às RS dos alunos. Entende-se, ainda, que as contribuições trazidas ao longo do texto podem suscitar reflexões e discussões nas escolas, pois, para que, de fato, haja melhoria na qualidade da educação, há necessidade, primeiramente, de mudança dentro das instituições escolares, no sentido de investir na construção de hábitos de estudo dos alunos não por imposição, mas por meio do diálogo e de negociações que favoreçam relações de cooperação entre alunos e professores. O ideal é que ambos saibam que sua postura deve ser "dialógica, aberta, curiosa e indagadora" (Freire, 1996, p. 86). No entanto, esse diálogo não pode desconsiderar a organização interna da RS do estudo, devido à função organizativa e defensiva do seu núcleo central. 


\section{Referências bibliográficas}

ABRIC. J. C. Abordagem estrutural das representações sociais: desenvolvimentos recentes. Tradução de Pedro Humberto Faria Campos. In: CAMPOS, P. H. F.; LOUREIRO, M. C. S. (Org.). Representações sociais e práticas educativas. Goiânia: Ed. UCG, 2003. p. 37-57.

ALVES-MAZZOTTI, A. J. O "aluno da escola pública": o que dizem as professoras. Revista Brasileira de Estudos Pedagógicos, Brasília, DF, v. 87, n. 217, p. 349-359, set./dez. 2006.

ALVES-MAZZOTTI, A. J. Representações da identidade docente: uma contribuição para a formação de políticas. Ensaio: Avaliação e Políticas Públicas em Educação, Rio de Janeiro, v. 15, n. 57, p. 579-594, out./dez. 2007.

AQUINO, J. G. Erro e fracasso na escola: alternativas teóricas e práticas. São Paulo: Summus, 1997.

BARDIN, L. Análise de conteúdo. Lisboa: Edições 70, 1977.

BARRETO, E. S. de S. Bons e maus alunos e suas famílias vistos pela professora de $1^{\circ}$ grau. Cadernos de Pesquisa, São Paulo, v. 37, p. 84-89, maio 1981.

BRASIL. Instituto Nacional de Estudos e Pesquisas Educacionais Anísio Teixeira (Inep). Programa Internacional de Avaliação de Alunos (PISA): resultados nacionais - PISA 2006. Brasília, DF: Inep, 2008. Disponível em: <http://download.inep.gov.br/download/internacional/pisa/ Relatorio_PISA2006.pdf>. Acesso em: 08 out. 2015.

BRASIL. Instituto Nacional de Estudos e Pesquisas Educacionais Anísio Teixeira (Inep). IDEB: resultados e metas. Escolas do estado do Paraná. 2011. Disponível em: <http://portalideb.inep.gov.br/index. php?option $=$ com_content\&task $=$ view\&id $=6 \&$ Itemid $=6>$. Acesso em: 14 jun. 2011.

BRASIL. Instituto Nacional de Estudos e Pesquisas Educacionais Anísio Teixeira (Inep). Prova Brasil: resultados. [s. d.]. Disponível em: <http:// sistemasprovabrasil.inep.gov.br/ProvaBrasilResultados/ $>$.

BUENO-ÁLVAREZ, J. A. Como fazer com que seus filhos estudem. Tradução de E. Verçosa Filho. São Paulo: Paulus, 2005.

CAMPOS, P. H. F. A abordagem estrutural e o estudo das relações entre práticas e representações sociais. In: CAMPOS, P. H. F.; LOUREIRO, M. C. S. Representações sociais e práticas educativas. Goiânia: Ed. UCG, 2003. p. 21-36. 
DESCHAMPS, J. C.; MOLINER, P. As representações sociais. In:

DESCHAMPS, J. C.; MOLINER, P. A identidade em Psicologia Social: dos processos identitários às representações sociais. Tradução de Lucia M.

Endlic Orth. Petrópolis: Vozes, 2009. p. 125-140.

FERNANDES, E. Psicologia da adolescência e da relação educativa. Porto: Edições Asa, 1990.

FERREIRA, M. C. R. (Org.). Os fazeres na educação infantil. São Paulo: Cortez, 2001.

FREIRE, P. Pedagogia da autonomia. São Paulo: Paz e Terra, 1996.

FREITAS, L. A moral na obra de Jean Piaget: um projeto inacabado. São Paulo: Cortez, 2003.

JODELET, D. Imbricações entre representações sociais e intervenção. In: MOREIRA, A. S. P.; CAMARGO, B. V. (Org.). Contribuições para a teoria e o método de estudo das representações sociais. João Pessoa: Ed. UFPB, 2007. p. 45-74.

JOVCHELOVITCH, S. Vivendo a vida com os outros: intersubjetividade, espaço público e representações sociais. In: GUARESCHI, P.;

JOVCHELOVITCH, S. (Org.). Textos em representações sociais. 5. ed. Petrópolis: Vozes, 1999. p. 63-85.

KAMII, C. Aritmética: novas perspectivas: implicações na teoria de Piaget. Tradução de Marcelo Cesari T. Lellis, Marta Rabioglio e Jorge José de Oliveira. Campinas: Papirus, 1993.

MAGRO, M. C. Estudar também se aprende. São Paulo: EPU, 1979.

MOSCOVICI, S. A psicanálise, sua imagem e seu público. Tradução de Sonia Fuhrmann. Petrópolis: Vozes, 2012.

MOSCOVICI, S. A representação social de psicanálise. Rio de Janeiro: Zahar, 1978.

NEVES, E. R. C.; BORUCHOVITCH, E. A motivação de alunos no contexto da progressão continuada. Psicologia: teoria e pesquisa, Brasília, DF, v. 20, n. 1, p. 77-85, jan./abr. 2004.

NUNES, C. O. C. Investigação sobre os hábitos de estudo e pesquisa de alunos do ensino médio. 2006. 127 f. Dissertação (Mestrado em Educação em Ciências e Matemática) - Pontifícia Universidade Católica do Rio Grande do Sul, Porto Alegre, 2006. 
OLIVEIRA, D. C. de; MARTINS, I. S. M.; FISCHER, F. M.; SÁ, C. P.; GOMES, A. M. T.; MARQUES, S. C. Pedagogia, futuro e liberdade: a instituição escolar representada por professores, pais e alunos. Psicologia: teoria e prática, São Paulo, v. 6, n. 3, p. 31-47, 2004.

OLIVEIRA, M. I. Fatores psicossociais e pedagógicos da indisciplina: da infância à adolescência. Linhas Críticas, Brasília, DF, v. 15, n. 29, p. 289305, jul./dez. 2009.

ORGANIZAÇÃO PARA A COOPERAÇÃO E DESENVOLVIMENTO ECONOMICO (OCDE). Conhecimentos e atitudes para a vida: resultados do PISA 2000. São Paulo: Moderna, 2000.

ORGANIZAÇÃO PARA A COOPERAÇÃO E DESENVOLVIMENTO ECONOMICO (OCDE). Aprendendo para o mundo de amanhã: primeiros resultados do PISA 2003. São Paulo: Moderna, 2005.

ORGANIZAÇÃO PARA A COOPERAÇÃO E DESENVOLVIMENTO ECONOMICO (OCDE). PISA 2009 results: learning to learn: student engagement, strategies and practices. v. 3. [Paris]: OCDE, 2010.

Disponível em: <http://www.oecd.org/pisa/pisaproducts/48852630. pdf $>$. Acesso em: 10 out. 2010.

PARANÁ. Secretaria de Estado da Educação do Paraná. SEED em números. 2012. Disponível em: <http://www4.pr.gov.br/escolas/ numeros/index.jsp>. Acesso em: 09 mar. 2012.

PIAGET, J. O juízo moral na criança. Tradução de E. Leonardon. São Paulo: Summus, 1994.

PREDIGER, J.; BERWANGER, L.; MÖRS, M. F. Relação entre aluno e matemática: reflexões sobre o desinteresse dos estudantes pela aprendizagem desta disciplina. Revista Destaques Acadêmicos, Lajeado, RS, v. 1, n. 4, p. 23-32, 2009.

ROSSO, A. J; CAMARGO, B. V. As representações sociais das condições de trabalho que causam desgaste aos professores estaduais paranaenses. Educação Temática Digital, Campinas, v. 13, n. 1, p. 269-289, jul./dez. 2011.

SÁ, C. P. Núcleo central das representações sociais. Petrópolis: Vozes, 1996.

SALLES, L. M. F. A representação social da escola e dos estudos de alunos da $8^{a}$ série e $1^{\circ}$ ano do colegial. Didática, São Paulo, v. 30, p. 81-96, 1995. 
SETÚBAL, M. A. Equidade e desempenho escolar: é possível alcançar uma educação de qualidade para todos? Revista Brasileira de Estudos Pedagógicos, Brasília, DF, v. 91, n. 228, p. 345-366, maio/ago. 2010.

SOUZA, C. P. de. A recuperação na escola. 3. ed. Brasília, DF: MEC/SEPS, 1985.

SPINK, M. J. A ética na pesquisa social: da perspectiva prescritiva à interanimação dialógica. Revista Semestral da Faculdade de Psicologia, Porto Alegre, v. 31, n. 1, p. 7-22, jan./jul. 2000.

TREVISOL, M. T. C. Indisciplina na escola: sentidos atribuídos por alunos do ensino fundamental. In: CONGRESSO INTERNACIONAL DE EDUCAÇÃO, 6., 2007, Concórdia. Anais... Concórdia: Ed. UnC, 2007. p. 1-18.

TURA, L. F. AIDS e estudantes: a estrutura das representações sociais. In: JODELET, D.; MADEIRA, M. C. (Org.) AIDS e representações sociais: à busca de sentidos. Natal: Ed. UFRN, 1998. p. 121-154.

VERGÉS, P. A. A evocação do dinheiro: um método para a definição do núcleo central de uma representação. In: MOREIRA, A. S. P.; CAMARGO, B. V.; JESUÍNO, J. C.; NOBREGA, S. M. (Ed.). Perspectivas teórico-metodológicas em representações sociais. João Pessoa: Ed. UFPB, 2005. p. 201- 228.

VERÍSSIMO. D. S.; ANDRADE, A. S. Estudo das representações sociais de professores de $1^{\mathrm{a}}$ a $4^{\mathrm{a}}$ série do ensino fundamental sobre a motivação dos alunos e o papel do erro na aprendizagem. Paidéia, Ribeirão Preto, v. 11, n. 20, p. 73-83, 2001.

VINHA, T. P.; TOGNETTA, L. R. P. Construindo a autonomia moral na escola: os conflitos interpessoais e a aprendizagem dos valores. Revista Diálogo Educacional, Curitiba, v. 9, n. 28, p. 525-540, set./dez. 2009.

Recebido em 11 de março de 2014 Solicitação de correções em 24 de março de 2015.

Aprovado em 13 de abril de 2015. 